\title{
Action Potential Backpropagation and Somato-dendritic Distribution of Ion Channels in Thalamocortical Neurons
}

\author{
Stephen R. Williams and Greg J. Stuart \\ Division of Neuroscience, John Curtin School of Medical Research, Australian National University, Canberra, \\ A.C.T. 0200, Australia
}

Thalamocortical (TC) neurons of the dorsal thalamus integrate sensory inputs in an attentionally relevant manner during wakefulness and exhibit complex network-driven and intrinsic oscillatory activity during sleep. Despite these complex intrinsic and network functions, little is known about the dendritic distribution of ion channels in TC neurons or the role such channel distributions may play in synaptic integration. Here we demonstrate with simultaneous somatic and dendritic recordings from TC neurons in brain slices that action potentials evoked by sensory or cortical excitatory postsynaptic potentials are initiated near the soma and backpropagate into the dendrites of TC neurons. Cell-attached recordings demonstrated that TC neuron dendrites contain a nonuniform distribution of sodium but a roughly uniform density of potassium channels across the so- matodendritic area examined that corresponds to approximately half the average path length of TC neuron dendrites. Dendritic action potential backpropagation was found to be active, but compromised by dendritic branching, such that action potentials may fail to invade relatively distal dendrites. We have also observed that calcium channels are nonuniformly distributed in the dendrites of TC neurons. Low-threshold calcium channels were found to be concentrated at proximal dendritic locations, sites known to receive excitatory synaptic connections from primary afferents, suggesting that they play a key role in the amplification of sensory inputs to TC neurons.

Key words: sodium channel; calcium channel; potassium channel; burst firing; patch clamp; dendrite; thalamus
Thalamocortical (TC) neurons of the dorsal thalamus integrate synaptic input from the periphery, neocortex, and brainstem to convey sensory information to the neocortex in an attentionally relevant and state-dependent manner (Steriade and Deschenes, 1984; McCormick, 1992; Steriade et al., 1993; Guido and Weyand, 1995; Sherman and Guillery, 1996). The complex electrophysiological properties of TC neurons serve to highlight their important integrative role (McCormick, 1992). Anatomical studies have revealed a precise organization of excitatory inputs from sensory and cortical inputs to the stem and relatively distal dendrites of TC neurons, respectively (Ralston and Herman, 1969; Sherman and Guillery, 1996). A similar anatomical segregation of inhibitory inputs from intrinsic and extrinsic GABAergic neurons may facilitate complex synaptic interactions in the dendrites of TC neurons (Sherman and Guillery, 1996). This synaptic organization highlights the need to directly investigate dendritic function in TC neurons.

Recent advances in recording techniques have allowed investigation of the distribution of voltage-activated channels that influence synaptic integration in the dendrites of several types of central neurons (Johnston et al., 1996; Stuart et al., 1997b). The complex radial, multi-branched fine caliber dendritic arbor of TC neurons (Grossman et al., 1973; Bloomfield et al., 1987; Havton and Ohara, 1993; Ohara and Havton, 1994; Ohara et al., 1995; Warren and Jones, 1997), however, has until now precluded direct

Received Sept. 17, 1999; revised Nov. 15, 1999; accepted Nov. 24, 1999

Correspondence should be addressed to Dr. Greg Stuart, Division of Neuroscience, John Curtin School of Medical Research, Mills Road, Australian National University, Canberra, A.C.T. 0200, Australia. E-mail: Greg.Stuart@anu.edu.au.

This work was supported by the Wellcome Trust and the Human Frontiers Science Program.

Copyright (C) 2000 Society for Neuroscience $\quad 0270-6474 / 00 / 201307-11 \$ 15.00 / 0$ analysis. Imaging, anatomical, and modeling studies have indicated that the dendrites of TC neurons contain voltage-activated calcium currents (Munsch et al., 1997; Zhou et al., 1997; Budde et al., 1998; Destexhe et al., 1998); however, the distribution and properties of these channels are unknown.

Simultaneous dendritic and somatic recording would allow investigation of the site(s) of action potential generation in TC neurons (Stuart et al., 1997b). Furthermore, once generated, action potentials may backpropagate into TC dendrites, where the complex dendritic branching of these neurons may influence action potential invasion (Spruston et al., 1995). Recent modeling studies have indicated that the geometry of the dendritic tree plays a key role in controlling the extent of active backpropagation of action potentials, with complex multi-branched dendritic arbors compromising this form of retrograde information transfer (Hausser et al., 1998). Similarly, modeling studies of branched cable and axonal structures have demonstrated that propagation of action potentials may fail or be compromised at branch points (Goldstein and Rall, 1974; Luscher and Shiner, 1990; Manor et al., 1991). The multi-branched structure of TC neuron dendrites, therefore, allows direct investigation of the role of dendritic branch points in the control of action potential backpropagation. The failure of action potential invasion into parts of a multibranched dendritic tree may have important functional outcomes. For example, backpropagating action potentials may invade some areas of the dendritic tree resetting synaptic integration but fail to influence activity in others (Spruston et al., 1995; Magee and Johnston, 1997; Stuart et al., 1997b; Stuart and Hausser, 1998).

Here we directly address these issues by making simultaneous whole-cell and cell-attached patch-clamp recordings from the soma and dendrites of TC neurons in slices of the dorsal lateral geniculate nucleus (dLGN). 


\section{MATERIALS AND METHODS}

Experiments were performed according to methods approved by the Animal Experimentation Ethics Committee of the Australian National University. Wistar rats (postnatal day 16-22) were decapitated, and $300-\mu \mathrm{m}$-thick brain slices of the dorsal lateral geniculate nucleus were prepared either in the plane of the optic tract (Crunelli et al., 1987b; Williams et al., 1996) or parasagittally (Turner and Salt, 1998). At this age, the synaptic, morphological, and electrophysiological properties of rat TC neurons are similar to those of adult animals (Perez Velazquez and Carlen, 1996; Warren and Jones, 1997; Warren et al., 1997; Golshani et al., 1998).

Slices were perfused with oxygenated Ringer's solution of the following composition (in mM): $125 \mathrm{NaCl}, 25 \mathrm{NaHCO}_{3}, 3 \mathrm{KCl}, 1.25 \mathrm{NaH}_{2} \mathrm{PO}_{4}$, $2 \mathrm{CaCl}_{2}, 1 \mathrm{MgCl}_{2}$, and 10 glucose. Experiments on action potential backpropagation were performed at $31-33^{\circ} \mathrm{C}$; all other experiments were conducted at room temperature $\left(20-24^{\circ} \mathrm{C}\right.$ ). Simultaneous somatic (pipette resistance 2-7 M $\Omega$ ) and dendritic (pipette resistance 10-15 M $\Omega$ ) patch-clamp recordings were made from visually identified TC neurons using two identical current-clamp amplifiers (Dagan) as previously described (Stuart and Sakmann, 1994). If the formation of a dendritic recording altered the somatic membrane potential or input resistance, both recordings were abandoned. A patch-clamp amplifier (Axon Instruments) was used in voltage and fast current-clamp mode for experiments involving the generation of a somatic action potential waveform in the presence of tetrodotoxin (TTX). Synaptic potentials were evoked with the use of a metal bipolar electrode or a patch pipette (1-2 M $\Omega$ ) placed within the optic tract, within the nucleus reticularis thalami to stimulate fibers of the cortical backprojection, or close (within $100 \mu \mathrm{m}$ ) to the recorded neuron. Synaptic responses were evoked at low frequency $(0.1-0.5 \mathrm{~Hz})$, usually in the presence of the $\mathrm{GABA}_{\mathrm{A}}$ receptor antagonist bicuculline methiodide. Somatic and dendritic cell-attached recordings (pipette resistance 12-15 M $\Omega$ ) were made using on-line leak subtraction $(\mathrm{P} / 4)$, and careful adjustment of pipette capacitance neutralization was made. No differences in the degree or time of negative pressure applied to the back of pipettes was required to form high resistance (3-10 G $\Omega$ ) seals at somatic and dendritic sites, suggesting that similar membrane areas were sampled. For whole-cell recordings, patch electrodes were filled with the following (in $\mathrm{mM}$ ): $135 \mathrm{~K}$-gluconate, $7 \mathrm{NaCl}, 10 \mathrm{HEPES}$, 0.5 EGTA, $2 \mathrm{Na}_{2}$-ATP, $0.3 \mathrm{Na}_{2}$-GTP, $10 \mathrm{Na}_{2}$-phosphocreatine, and 2 $\mathrm{MgCl}(\mathrm{pH} 7.2$ adjusted with $\mathrm{KOH}$; osmolarity $270 \mathrm{mOsm}$ ). No correction was made for liquid junction potentials. For cell-attached recordings of $\mathrm{Na}$ and $\mathrm{K}$ currents, patch electrodes contained (in $\mathrm{mM}$ ): $135 \mathrm{NaCl}, 3 \mathrm{KCl}$, $1 \mathrm{CaCl}_{2}, 2 \mathrm{MgCl}_{2}, 3 \mathrm{NiCl}_{2}, 0.5 \mathrm{CdCl}_{2}, 10$ HEPES, and 10 glucose, $\mathrm{pH} 7.2$; whereas for recordings of $\mathrm{Ca}^{2+}$ currents, electrodes contained $140 \mathrm{mM}$ tetraethylammonium chloride (TEA), $10 \mathrm{~mm} \mathrm{BaCl}_{2}, 2 \mathrm{~mm} \mathrm{MgCl}_{2}, 1 \mathrm{~mm}$ $\mathrm{CsCl}_{2}, 3 \mathrm{~mm}$ 4-aminopyridine, $1 \mu \mathrm{M}$ TTX, and $10 \mathrm{~mm}$ HEPES (pH 7.2 adjusted with Tris-base solution) (Mouginot et al., 1997). For whole-cell recordings, voltage and current signals were filtered at 10 or $30 \mathrm{kHz}$, whereas for cell-attached recordings current signals were filtered at 2-5 $\mathrm{kHz}$. Signals were acquired at $20-100 \mathrm{kHz}$, using an ITC-16 interface (Instrutech Corporation, Long Island, NY) controlled by an Apple PowerPC implementing Axograph acquisition and analysis software (kindly supplied by Dr. J. Clements, Division of Neuroscience, Australian National University). Maximal conductance was calculated with an equation of the form $g=I /\left(V_{\mathrm{T}}-V_{\text {rev }}\right)$, where $I$ is the recorded current, $V_{\mathrm{T}}$ is the test voltage, and $V_{\text {rev }}$ is the reversal potential extrapolated from current-voltage relationships. Steady-state activation and inactivation curves were fit with a single Boltzmann equation of the form: $y=1 /(1+$ $\left.e^{(\mathrm{V} 1 / 2-\mathrm{V}) / \mathrm{k}}\right)$, where $V_{1 / 2}$ is the voltage of half-maximal activation or inactivation, and $k$ is a constant. The rise and decay of outward currents were fit with an equation of the form $y=a\left(1-e^{(-\mathrm{t} / \tau \text { rise })}\right)^{\mathrm{G}} \cdot\left(e^{(-\mathrm{t} /}\right.$ $\tau$ decay) $+c)$, where $t$ is time, $\tau_{\text {rise }}$ and $\tau_{\text {decay }}$ are the time constants of rise and decay, $b$ is the power of the activation process (Huguenard et al., 1991), and $a$ and $c$ are scaling factors. Numerical values are given in the text as mean \pm SEM, unless stated otherwise. Statistical analysis was performed with either Student's $t$ test or ANOVA, with statistical significance determined with $\alpha=0.05$.

\section{RESULTS}

The dendritic morphology of TC neurons is well preserved in slices of the rat dLGN (Crunelli et al., 1987b; Williams et al., 1996). These neurons exhibit radial dendritic trees, with 3-10 stem dendrites, that branch to form second to seventh order terminal dendrites (Williams et al., 1996). The dendritic path length (length from origin to termination) has been found to be on average $151 \mu \mathrm{m}$ (range 58-193 $\mu \mathrm{m}$ ) in TC neurons of the adult rat somatosensory thalamus (Ohara and Havton, 1994). In the present investigation, dLGN TC neurons were visually identified using interference contrast video microscopy (see Fig. 5B) by their relatively large round somata and the presence of three or more stem dendrites, which had diameters of $\sim 1-3 \mu \mathrm{m}$. This method of identification was confirmed by somatic whole-cell recordings that revealed characteristic electrophysiological properties of TC neurons, namely a robust low-threshold calcium potential and a highly rectified voltage-current relationship (Williams et al., 1996).

\section{Initiation and backpropagation of action potentials}

Simultaneous whole-cell current-clamp recordings were made from the soma and dendrites of TC neurons. Electrical stimulation of the sensory input (optic tract) $(n=6)$ or cortical backprojection $(n=8)$ evoked EPSPs that led to the generation of either a single or high-frequency burst of action potentials in a voltage-dependent manner (Fig. $1 A, C$ ). This corresponds to the two action potential firing modes of TC neurons (Deschenes et al., 1982; Llinas and Jahnsen, 1982). Burst firing is known to be driven by the activation of low-threshold calcium $\left(I_{\mathrm{T}}\right)$ channels, which form a transient depolarizing potential termed a lowthreshold calcium potential (LTCP) (Crunelli et al., 1987a; Llinas, 1988; Coulter et al., 1989; Hernandez-Cruz and Pape, 1989; McCormick, 1992; Steriade et al., 1993). This LTCP has recently been suggested to be generated by $I_{\mathrm{T}}$ channels located in the distal dendrites of TC neurons (Destexhe et al., 1998). Activation of these calcium channels may therefore lead to dendritic depolarization sufficient to evoke dendritic action potential initiation, as has been shown in other central neurons after intense distal dendritic depolarization (Schiller et al., 1997; Stuart et al., 1997a; Golding and Spruston, 1998).

Under all conditions, EPSPs led to the generation of single or LTCP-driven bursts of action potentials that were always recorded first at the somatic recording electrode $(n=14)$ (Fig. $1 A, C$, insets). In an attempt to depolarize the dendrites of TC neurons to a greater extent to search for dendritic action potential initiation, we repetitively stimulated the sensory and cortical inputs (Fig. 1B,D). Repetitive stimulation of the sensory input led to profound frequency-dependent depression of EPSPs (Fig. $1 B)$; the summated series of EPSPs, however, always evoked action potentials that were recorded first somatically $(n=6)$ (Fig. $1 B$, inset). In contrast, repetitive stimulation of the cortical backprojection led to frequency-dependent facilitation, where each EPSP of a train increased in amplitude (Fig. 1D). This form of input depolarized neurons to such an extent that action potentials were inactivated and replaced by the generation of slower regenerative events (Fig. 1D, bottom inset) (Turner and Salt, 1998). Despite this powerful form of distal dendritic depolarization, all action potentials and slow regenerative events were recorded first from somatic sites $(n=8)$ (Fig. $1 D)$, indicating that action potential initiation does not occur in TC neuron dendrites.

To further explore the site of action potential initiation in TC neurons, we evoked action potentials by the injection of current at the soma or at the dendritic recording site $(n=40)$ (Fig. $2 A)$. In all neurons examined, action potentials were first recorded at the soma and then backpropagated into the dendritic tree. Action potential backpropagation was found to be decremental, with the degree of attenuation related to the dendritic recording location. The effects of recording location are summarized in Figure $2 A$, 

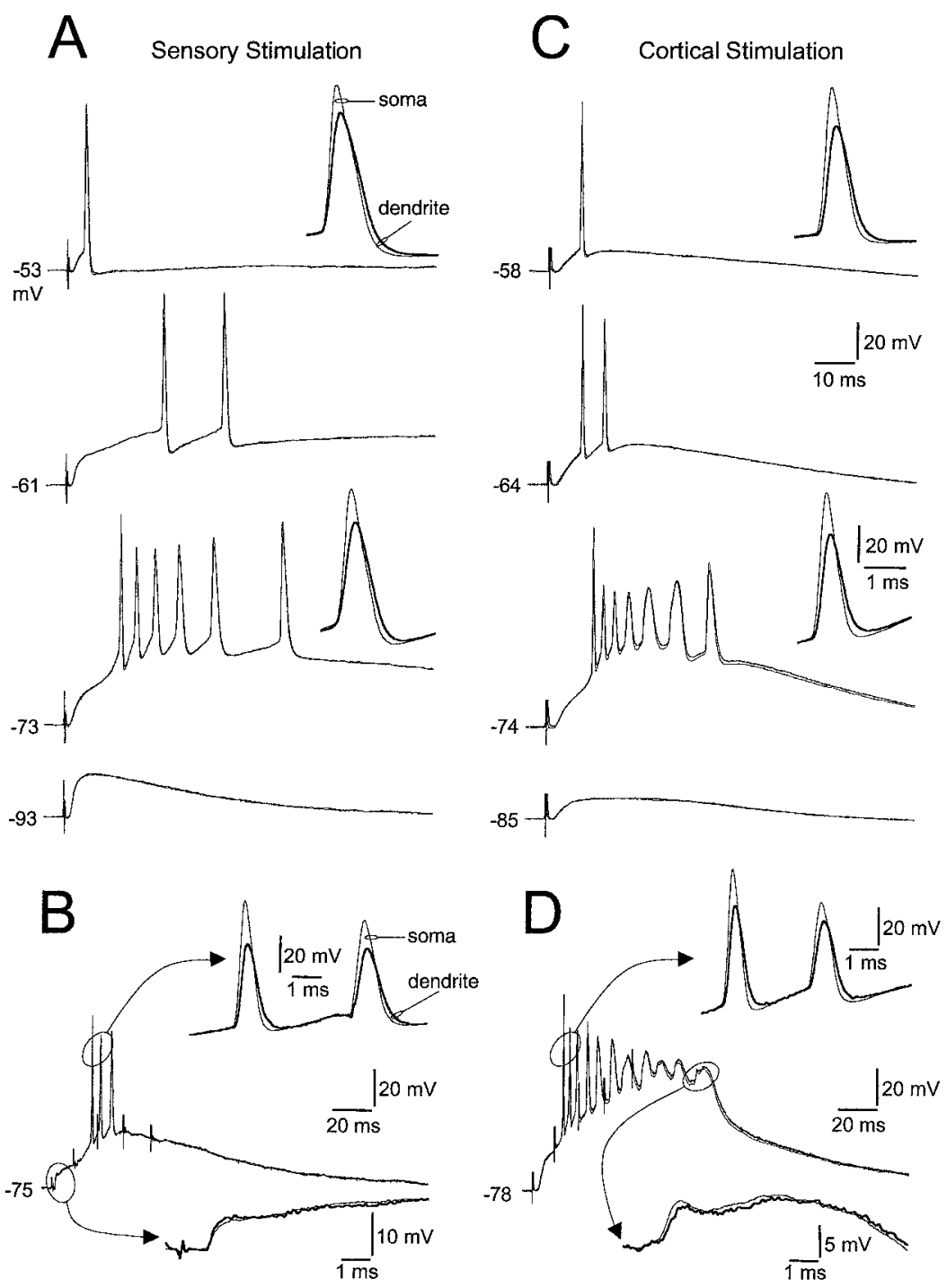

Figure 1. EPSPs evoke action potentials that backpropagate into the dendrites of TC neurons. $A$, Simultaneous somatic and stem dendritic ( $25 \mu \mathrm{m}$ from the soma/dendritic intersection) recording of action potentials evoked by electrical stimulation of fibers of the optic tract. EPSPs led to the generation of a single or a burst discharge of action potentials, in a voltage-dependent manner. Membrane potential (indicated to the left of traces) was controlled by the tonic passage of current through the somatic electrode. The inset shows the first somatic and dendritic (thick trace) action potential at a faster time base. Note that action potentials are recorded first at the soma. $B$, Repetitive stimulation $(5$ stimuli at $100 \mathrm{~Hz}$ ) of optic tract fibers evoked EPSPs that depress during the train. The top inset shows superposed somatic and dendritic action potentials, and the bottom inset the rising phase of the first EPSP of the train. Note that the EPSP rise time is faster in the dendritic recording made from a secondary dendrite $37 \mu \mathrm{m}$ from the soma/dendritic intersection. $C$, Action potential discharge evoked by electrical stimulation of fibers of the corticothalamic tract. The dendritic recording was made from a stem dendrite $35 \mu \mathrm{m}$ from the soma/dendritic intersection. The inset shows the first somatic and dendritic (thick trace) action potential at a faster time base. Note that action potentials are recorded first at the soma. $D$, Repetitive stimulation of this pathway evoked EPSPs that showed frequency-dependent facilitation. The top inset shows superposed somatic and stem dendritic ( $30 \mu \mathrm{m}$ from the soma/ dendritic intersection) action potentials, and the bottom inset shows slow regenerative potentials at a faster time base. where dendritic recordings were sequentially made at the first dichotomous branch point, from its stem dendrite, and from one of its daughter dendrites of the same neuron. Note that the amplitude and shape of backpropagating dendritic action potentials are dramatically altered at and after the dendritic branch point. Pooled data derived from simultaneous somatic and dendritic recordings $(n=27)$ demonstrated that when dendritic recordings were made from a stem dendrite, the amplitude of dendritic action potentials decreased, on average, by $3.8 \%$ per 10 $\mu \mathrm{m}$ (distances from soma/dendrite intersection) (Fig. $2 B, \bigcirc$ ). Dendritic recordings made from higher order (second or third) dendrites $(n=13)$ revealed that action potential attenuation was increased after dendritic branching, proceeding with a steeper average slope of $9 \%$ per $10 \mu \mathrm{m}$ (Fig. $2 \mathrm{~B}, \mathbf{9}$ ). To ascertain in any given dendrite whether a branch point-induced decrease in action potential backpropagation occurred, recordings were made from the same dendrite at sites before and after a branch. For an average dendritic electrode separation of $16.5 \mu \mathrm{m}$, an average decrease in action potential amplitude of $27.4 \%$ was observed (Fig. 2B, inset). This value is greater than that found for action potential attenuation along an unbranched dendrite, emphasizing the deleterious effects of dendritic branching on action potential backpropagation. The attenuation of slower voltage changes of the membrane were measured by plotting the degree of steadystate voltage attenuation from soma to dendrite (determined at the termination of small, negative, $200-500 \mathrm{msec}$ somatic current steps that evoked voltage deviations of $<5 \mathrm{mV}$ at the soma). The degree of steady-state attenuation was found to be $2.9 \%$ per 10 $\mu \mathrm{m}$ along stem dendrites and $4 \%$ per $10 \mu \mathrm{m}$ when recordings were made after dendritic branching (Fig. $2 \mathrm{C}$ ), indicating that steady-state attenuation is not noticeably effected by dendritic branching. The relationship between action potential and steadystate voltage attenuation was found to be close to 1 for recordings made from stem dendrites, but $<1$ for recordings made after dendritic branching (Fig. 2D). This suggests that action potential backpropagation is active; that is, it is reliant on the activation of dendritic voltage-activated ionic currents, because a near-unity relationship between action potential and steady-state attenuation in stem dendrites would not be expected for a passive system.

\section{Distribution of sodium and potassium channels}

Somatic and dendritic cell-attached recordings $(n=46)$ were used to map the distribution and basic properties of sodium and potassium channels. From a pipette voltage of $0 \mathrm{mV}$ [i.e., from the resting membrane potential (RMP) of the cell], a $-40 \mathrm{mV}, 500$ msec prepulse was used to remove steady-state inactivation, fol- 
Figure 2. Action potential backpropagation into the dendrites of TC neurons. $A$, Simultaneous somatic and dendritic recordings of action potentials evoked by somatic current injection. Dendritic recordings were sequentially made from the first branch point of a stem dendrite $(35 \mu \mathrm{m}$ from the soma/dendrite intersection), from the stem dendrite (20 $\mu \mathrm{m})$, and from one of its daughter dendrites $(62 \mu \mathrm{m})$. Note changes in action potential onset, the abrupt decrease in amplitude, and increase in action potential duration for recordings made at and after the dendritic branch point. $B$, Pooled data demonstrate the relationship between action potential amplitude and dendritic recording location for recordings made from stem $(\bigcirc)$ and higher order $(\bullet)$ dendrites. All data from simultaneous somatic and dendritic recordings. The average amplitude of somatic action potentials $( \pm \mathrm{SD})$ is shown as the filled square. Lines represent regression analysis, constrained to the average somatic action potential amplitude. The inset shows the degree of reduction of action potential amplitude for recordings made before $(\bigcirc)$ and after $(\bullet)$ a branch point from the same dendrite. $C$, Normalized steady-state attenuation of small negative voltage responses evoked at the soma for recordings made from stem $(\bigcirc)$ and higher order dendrites $(\bullet)$. Lines represent regression analysis, constrained at origin to 1. $D$, Relationship between normalized steady-state attenuation and normalized action potential attenuation for recordings made from stem $(O)$ and higher order dendrites $(\bullet)$; the line has a slope of 1 .

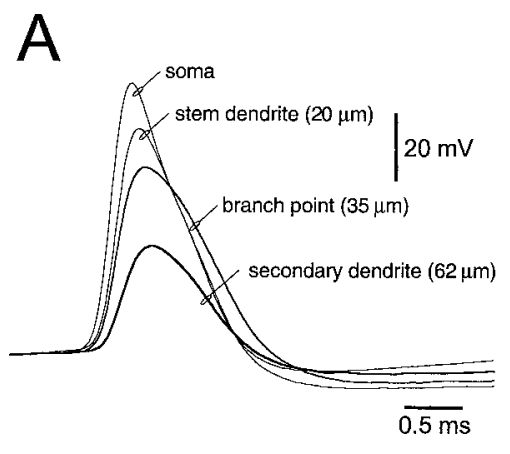

B
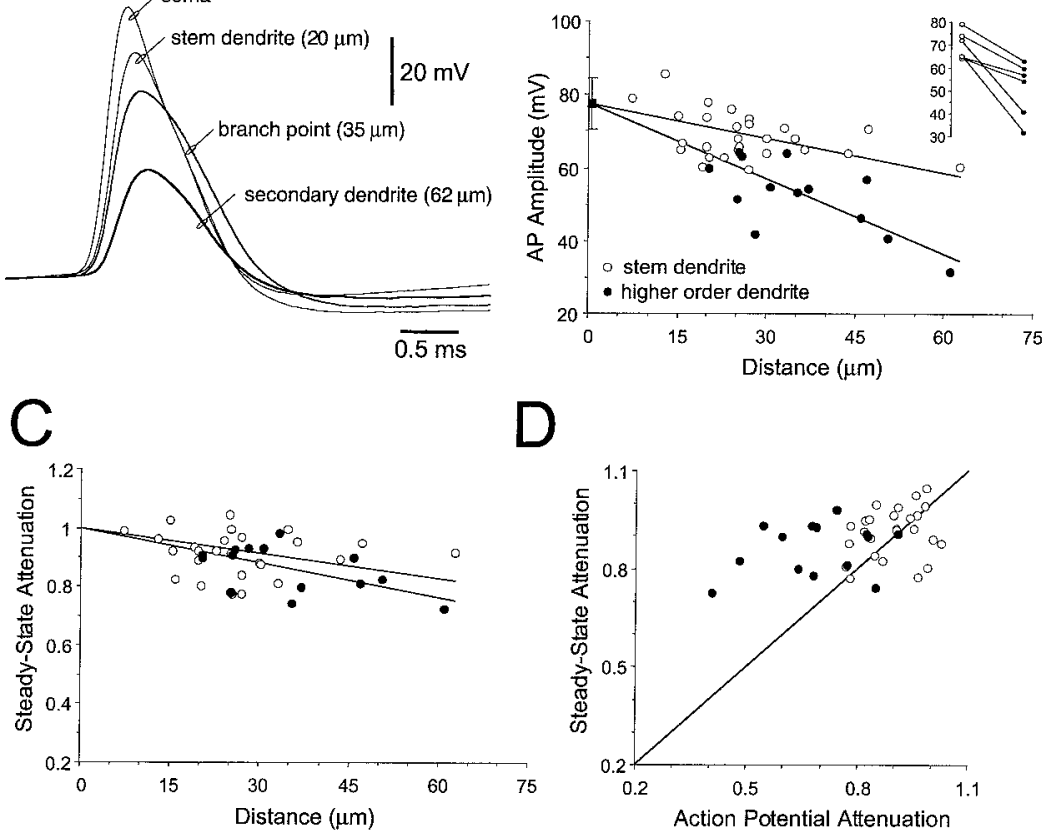

D

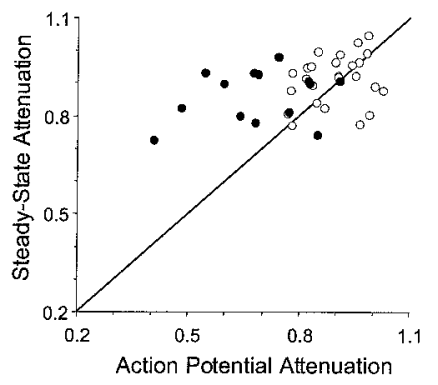

A

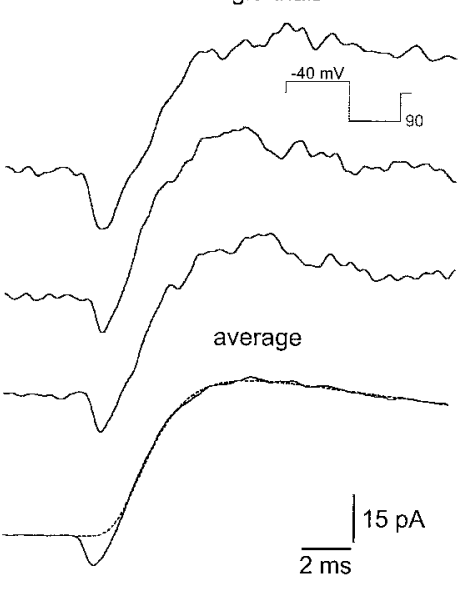

B

activation

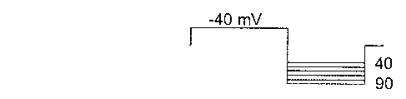

Figure 3. Properties and somato-dendritic distribution of sodium channels. $A$, Three consecutive single sweeps of cell-attached patch currents recorded from a stem dendrite. Note the clear appearance of a fast inward current followed by a slower outward current. The bottom trace is an average ( $n=30$ trials), and the dashed line represents a fit to the rising and decaying phase of the outward current (see Materials and Methods). Note that extrapolation of this fit indicates that there is no significant outward current activation at the time of the peak of the inward current. The voltage protocol is shown as an inset. $B$, Superposed averaged ( $n=5$ trials) cell-attached current records demonstrate the voltage dependence of activation of the fast inward current; data were obtained from a dendritic primary branch point. The dashed lines represent fits made to the rise and decay of the outward current. The voltage protocol is shown as an inset. $C$, Pooled data demonstrating the somatodendritic distribution of the fast inward (sodium) current during test pulses to $+90 \mathrm{mV}$, as shown in $A$. The line is an unconstrained regression fit. Filled squares show mean ( \pm SD) current as a function of distance from the soma ( \pm SD) for recordings made from the soma, stem dendrites, primary branch points. and higher order dendrites (from left to right, respectively). Note that for higher order dendrites the amplitude of the fast inward (sodium) current is on average reduced. $D$, Normalized current-voltage relationship. Families of currents for a single neuron were normalized to the maximal value, and then data from different neurons were pooled $(n=13)$.
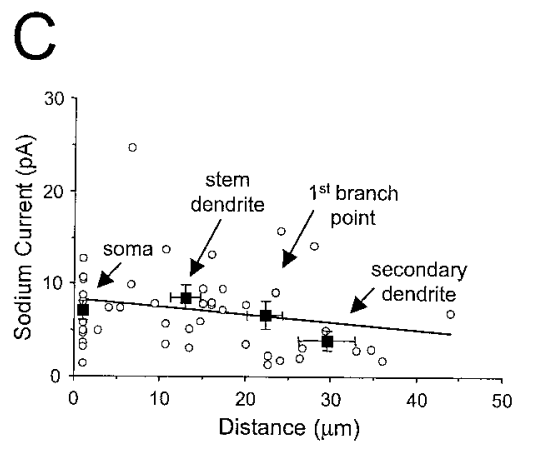

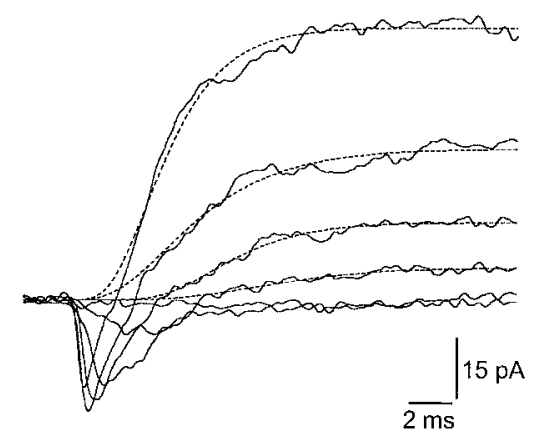

D

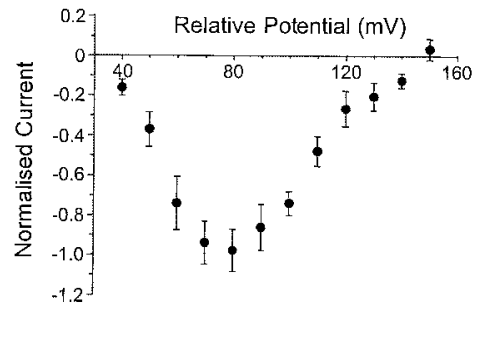

lowed by a positive test pulse to $+90 \mathrm{mV}$. The mean whole-cell RMP of neurons was $-73 \pm 1 \mathrm{mV}$; therefore, the voltage change of the membrane will be from approximately $-113 \mathrm{mV}$ to +17 $\mathrm{mV}$. When the contribution of a liquid-junction and Donnan equilibrium potentials are considered (Verheugen et al., 1999), however, the true resting potential of neurons is probably closer to $-80 \mathrm{mV}$. Figure 3 demonstrates examples of cell-attached patch currents during steps to these test potentials, which were characterized by a fast transient inward current followed by a bi-phasic outward current. This ensemble channel activity was variable from trial to trial (Fig. $3 A$ ). An incremental series $(+30$ to $+150 \mathrm{mV}$ ) of positive test pulses were used to establish the 
nature of these currents (Fig. $3 B$ ). The fast inward current first activated $\sim 40 \mathrm{mV}$ positive to RMP, peaked close to $\sim 80 \mathrm{mV}$ positive to RMP, and demonstrated voltage-dependent activation kinetics (Fig. 3B,D). This current was substantially inactivated by omitting the hyperpolarizing prepulse or applying small positive (20 $\mathrm{mV}$ ) prepulses (data not shown). Given that calcium currents were blocked under our recording conditions, this cell-attached inward current is most likely a fast sodium current $\left(I_{\mathrm{Na}}\right)$ (Parri and Crunelli, 1998). The amplitude of $I_{\mathrm{Na}}$ was found to be variable from patch to patch, but on average it was similar for recordings made from the soma, stem dendrites, and at the first dendritic branch point (Fig. $3 C$ ). The average amplitude of $I_{\mathrm{Na}}$ in recordings made from higher order dendrites was found, however, to be relatively smaller than those recorded from the soma ( $p<$ $0.05, t$ test) (Fig. $3 C$ ). At the test potential used to assess sodium channel density, the amplitude of the fast inward current was minimally distorted by the presence of outward currents because the activation of outward currents was relatively slow and possessed a sigmoidal time course. The predicted time course of the outward current is shown by extrapolation from fits made to the rise and decay of the outward current in Figure $3 A, B$. Note that at the peak of $I_{\mathrm{Na}}$ little outward current is activated.

$I_{\mathrm{Na}}$ was followed by a bi-phasic outward current, which was characterized by a relatively fast transient component that, in turn, was followed by a more sustained component (Fig. 4A,B). The relative fraction of these kinetically distinct components was variable at different locations in the same neuron (Fig. $4 A$ ). The amplitude of the transient current was calculated by subtraction of the value of the steady-state current at the end of the test pulse (used to measure the sustained current) from the peak of the current. We observed that some patches appeared to contain only one of these components (data not shown). On average, however, despite a large degree of interpatch variability, these channels were found to be uniformly distributed on the soma, stem, and higher order dendrites (Fig. $4 C, D$ ). The uniform density of outward currents is in contrast to that of $I_{\mathrm{Na}}$, indicating that any contamination of $I_{\mathrm{Na}}$ measurement by potassium currents would be similar at all somato-dendritic locations. The kinetic properties (Fig. $4 B$ ) of these ensemble channel activities are similar to the transient $I_{\text {A-like }}$ and more slowly inactivating delayed rectifier potassium currents identified by whole-cell recording in TC neurons (Huguenard and Prince, 1991; Huguenard et al., 1991). Furthermore, the transient component of the current was found to activate from more hyperpolarized membrane potentials (Fig. $4 B)$, as is the case for whole-cell $I_{\text {A-like }}$ currents. It should be noted, however, that the voltage dependence of activation of this transient outward current may have been shifted in the depolarized direction by the inclusion of calcium channel blockers in the patch pipette-filling solution (Mayer and Sugiyama, 1988; Klee et al., 1995). In summary, cell-attached recordings demonstrate that potassium channels are localized in the dendrites of TC neurons at densities similar to those of the soma.

\section{Active action potential backpropagation}

To directly test the influence of dendritic voltage-activated channels on backpropagation of action potentials, we made simultaneous whole-cell somatic and dendritic recordings under control conditions, and then for each neuron examined $(n=16)$ we used the somatically recorded action potential as a somatic voltageclamp command waveform to ascertain action potential attenuation in the presence of the sodium channel blocker TTX (Stuart and Sakmann, 1994). In these experiments care was taken to
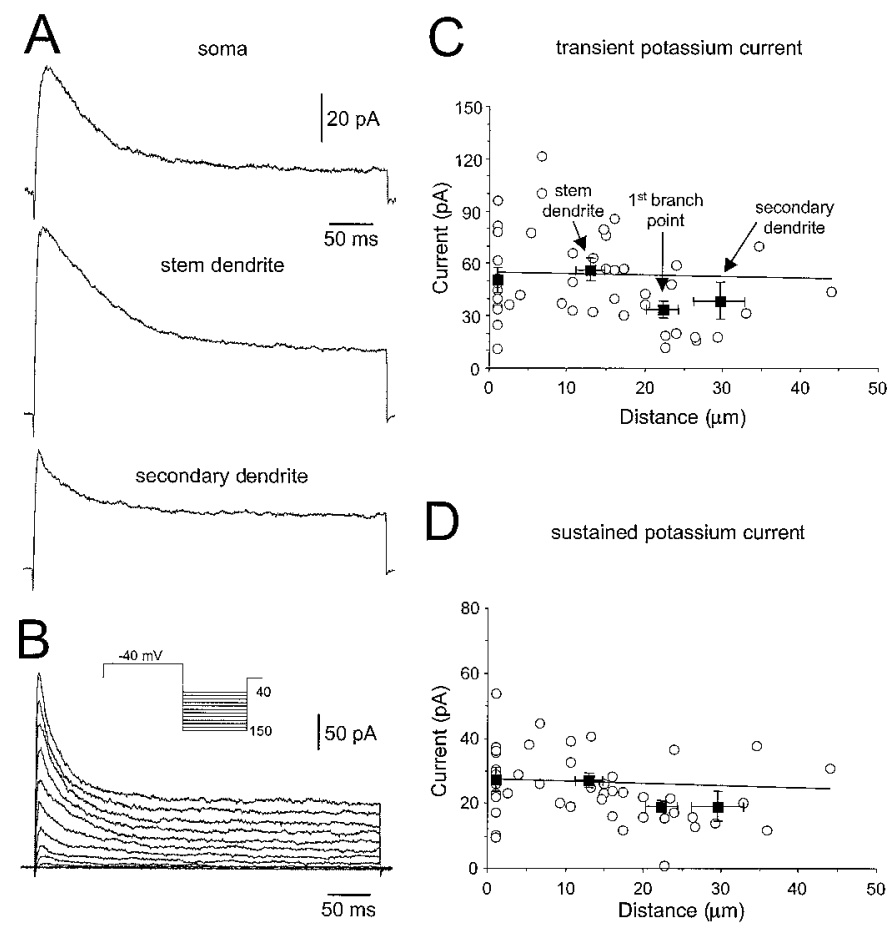

Figure 4. Properties and somato-dendritic distribution of potassium channels. $A$, Averaged ( $n=30$ trails) cell-attached patch currents obtained from the indicated somato-dendritic locations of a single neuron. Note that the amplitude and the relative contribution of the transient and sustained outward currents is variable from patch to patch. $B$, A family of superposed cell-attached patch currents demonstrate the voltagedependent activation properties of the transient and sustained outward currents, obtained from a stem dendritic patch. The voltage protocol is shown as an inset. $C$, Pooled data demonstrating the somato-dendritic distribution of the transient outward current. The line is an unconstrained regression fit. Filled squares show mean $( \pm \mathrm{SD})$ current as a function of distance from the soma $( \pm \mathrm{SD})$ for recordings made from the soma, stem dendrites, primary branch points, and higher order dendrites (from left to right, respectively). $D$, Pooled data demonstrating the somato-dendritic distribution of the sustained outward current, as in $C$.

achieve stable, low series resistance somatic recordings $(<8 \mathrm{M} \Omega$, pipette resistance 2-3 $\mathrm{M} \Omega$, which was compensated for by $>95 \%$, in the presence of lag values of $<3 \mu \mathrm{sec}$ ). Using this technique we observed that the blockade of sodium channels by bath application of TTX greatly reduced the amplitude of dendritic action potentials (Fig. $5 A, C$ ), decreasing the slope of action potential attenuation with distance from $4.3 \%$ per $10 \mu \mathrm{m}$ to $11.9 \%$ per 10 $\mu \mathrm{m}$. To verify the voltage change at the soma produced by the injection of action potential voltage-command waveforms, we made subsequent double somatic recordings in 10 of 16 neurons and observed that the voltage change produced was on average $95.8 \%$ of the original somatic action potential amplitude (Fig. $5 A, C)$. These findings, therefore, directly demonstrate that action potential backpropagation in TC neurons is active and dependent on dendritic sodium channel activation.

\section{Dendritic filtering of action potential burst firing}

During burst firing, the attenuation of the first action potential of a burst mirrored that of action potentials evoked in single-spike firing mode (slope reduction along stem dendrites $4.2 \%$ per 10 $\mu \mathrm{m}$; after branch points $9.1 \%$ per $10 \mu \mathrm{m}$ ). Each action potential of a burst was recorded first at soma. Surprisingly, however, we observed that when backpropagating action potentials were re- 

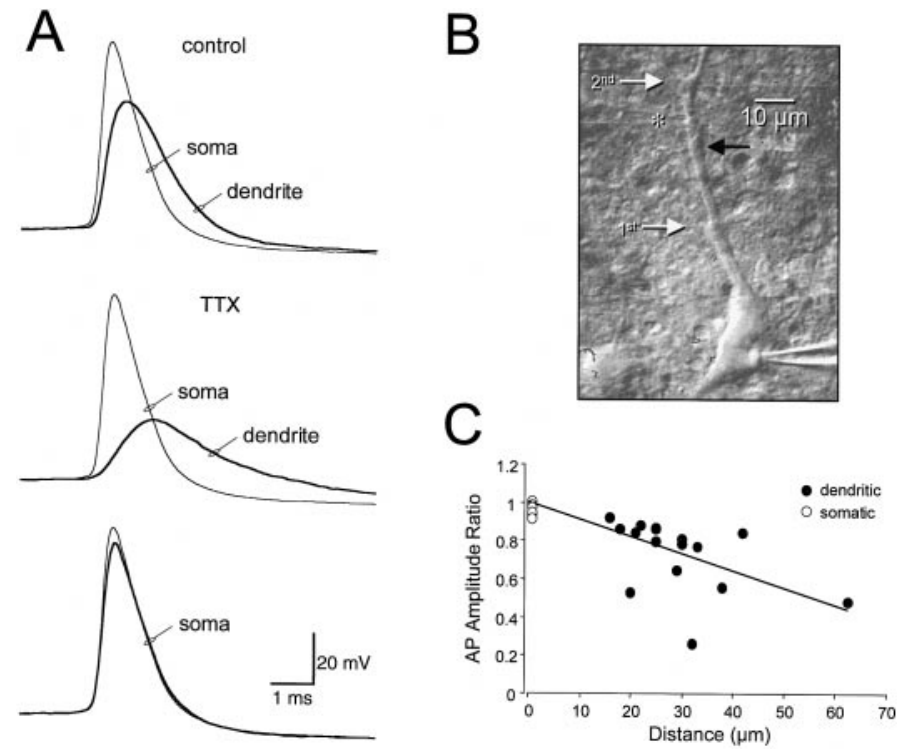

Figure 5. Active dendritic action potential backpropagation. A, The top traces show simultaneous somatic and dendritic whole-cell current-clamp recordings demonstrating action potential attenuation under control conditions. The soma was then voltage-clamped, and the control somatic action potential was used as a voltage command. The middle traces demonstrate the relatively small dendritic voltage response evoked by the somatic action potential voltage command in the presence of the sodium channel blocker tetrodotoxin (TTX). The bottom traces show the actual voltage deviation produced at the soma by the somatic action potential voltage command (thick trace) during double somatic recording. B, Video image of the neuron and the location of somatic and dendritic (white asterisk) recording electrodes. The white arrows show the location of major dendritic branch points, and the black arrow indicates a small collateral dendrite. $C$, Pooled data from 16 experiments showing the ratio of dendritic action potential amplitude in the presence of TTX versus that in control at different dendritic locations. The ratio of voltage changes recorded at the soma during control and in TTX, obtained during double somatic recordings, is shown as open circles. The line represents the result of linear regression analysis.

corded after dendritic branch points, the degree of attenuation of subsequent action potentials in a burst was less than that of the first (Fig. 6A). When recorded from the soma, later action potentials in a burst showed a reduction in amplitude and a slowing of rise and decay times (Fig. 6A). Backpropagating action potentials recorded after dendritic branch points, however, showed an apparent equalization of amplitude, where the first action potential of a burst was attenuated to the greatest extent (slope reduction along stem dendrites for third action potential of a burst $3.7 \%$ per $10 \mu \mathrm{m}$; after branch points $7.4 \%$ per $10 \mu \mathrm{m}$ ) (Fig. $6 A$ ). This effect is quantified in Figure $6 B$ by plotting the difference in amplitude of the first and third action potentials recorded at the soma, relative to their differential amplitude when recorded dendritically. Along stem dendrites, a near unity relationship exists that collapses after dendritic branching (Fig. 6B). These effects were not a consequence of sodium channel activation/inactivation because they were also observed in the presence of TTX, after the injection of a voltage-clamp waveform composed of an action potential burst at the soma. Furthermore, scaling of this burst voltage-clamp waveform by one-half did not modify the normalization of dendritic action potential amplitude (data not shown), suggesting that these effects are not dependent on the influence of potassium or calcium channels but are likely to reflect the more effective passive propagation through dendritic branch points of
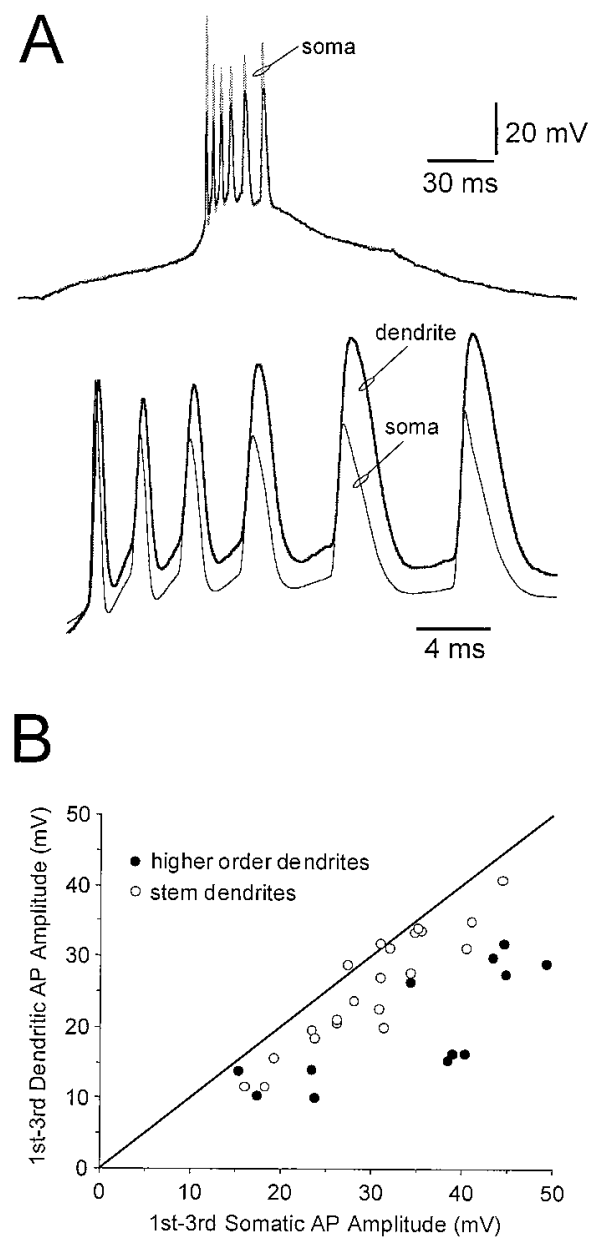

Figure 6. Filtering of action potential burst firing by dendritic branch points. A, Top, Simultaneous somatic (thin trace) and secondary dendritic (thick trace) whole-cell recordings during a burst of action potentials evoked by somatic current injection. Note that the amplitude of somatic action potentials decreases during the burst, but the amplitude of dendritic action potentials increases. Bottom, This effect is shown more clearly at a faster time base, where the first dendritic action potential (thick trace) has been scaled to equal the amplitude of the first somatic action potential. $B$, The relative difference in first and third action potential amplitude, when measured from the soma and dendrite. Note a near-unity relationship exists for recordings made from stem dendrites $(\bigcirc)$, but this relationship collapses after dendritic branching $(\bullet)$.

the slowly rising and broader action potentials that occurred later in the burst.

\section{Properties of calcium channels in cell-attached patches}

Cell-attached recordings, made in the presence of TTX and with a TEA-based, barium-rich pipette solution $(n=60)$, demonstrated that an isolated transient inward current was evoked in both the soma and dendrites in response to voltage steps from approximately -113 to $-33 \mathrm{mV}$ (Fig. $7 A$ ). This cell-attached current was of low amplitude, variable from trial to trial, but clearly discernible in single trials (Fig. 7A). An increase in test pulse amplitude led to the additional appearance of a sustained inward current in some patches (Fig. 7B). The construction of current-voltage relationships revealed that this transient inward current was first activated from potentials $\sim 20 \mathrm{mV}$ positive to $\mathrm{RMP}$, reaching a peak at $\sim 75 \mathrm{mV}$ positive to RMP, whereas the sustained component was first activated from potentials $\sim 50 \mathrm{mV}$ 

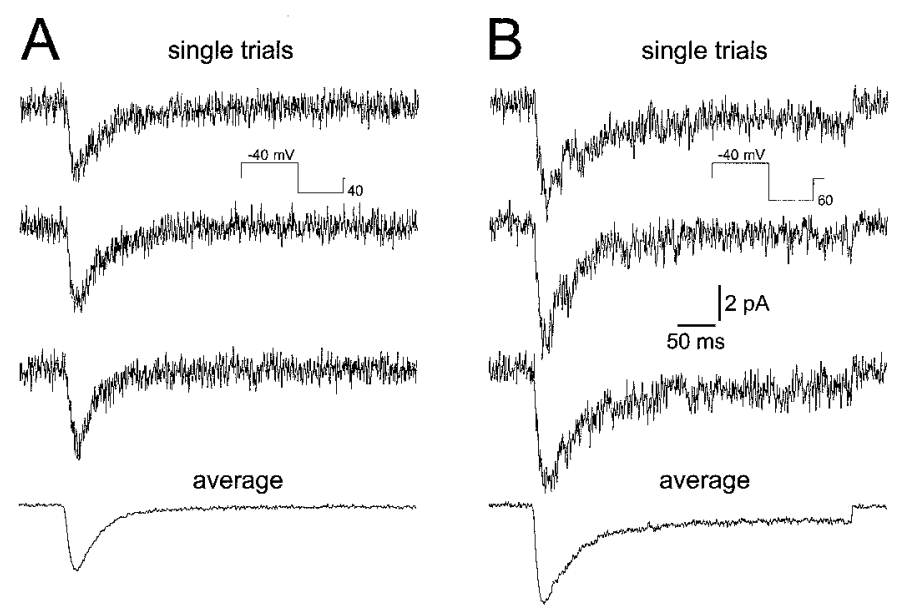

Figure 7. Calcium channel activation in the dendrites of TC neurons. $A$, Cell-attached patch currents recorded from a secondary dendrite with pipette solutions designed to block sodium and potassium currents (see Materials and Methods). Three sequential single trials demonstrate the presence of an isolated transient inward current, which is shown more clearly in the average ( $n=50$ trials). The voltage protocol is shown as an inset. $B$, An additional sustained current was evoked by increasing the magnitude of the test pulse.

positive to RMP (Fig. $8 A, C$ ). The kinetics of activation and inactivation of the transient current were found to be voltage dependent (Fig. 8A). Furthermore, the transient inward current could be steady-state inactivated by applying prepulses (1 sec duration) of varying amplitude (Fig. $8 B$ ). We constructed steadystate activation and inactivation curves for ensemble $\mathrm{I}_{\mathrm{T}}$ currents recorded from the majority of patches (Fig. $8 D$ ). When pooled from all recording sites, steady-state activation and inactivation curves were found to be well fit with single Boltzmann functions, with slopes of 13.6 and 11.8, respectively. A better approximation of the steady-state activation curve could be made, however, by raising the Boltzmann function to the third power (Fig. 8D). A considerable voltage overlap was found between these curves, indicating that under ideal voltage-clamp conditions a nonnegligible window current exists (Fig. 8D) (Williams et al., 1997). Furthermore, the slope of these steady-state curves was found to be shallower than those reported for whole-cell recordings made from intact or dissociated TC neurons (Coulter et al., 1989; Crunelli et al., 1989; Destexhe et al., 1998). This was not a product of data pooling because we observed steepness values of between 5.5 to 16.6 (activation) and 7.6 to 19.9 (inactivation) in individual recordings, indicating that previous estimates of these parameters may have been compromised by the recording configuration and conditions (Destexhe et al., 1998). These voltagedependent and kinetic properties identify the transient inward current as a low-threshold calcium current, $I_{\mathrm{T}}$, and the sustained current as a high-threshold calcium current (Coulter et al., 1989; Crunelli et al., 1989; Hernandez-Cruz and Pape, 1989; Mouginot et al., 1997).

\section{Distribution of low-threshold calcium channels}

We mapped the distribution of $I_{\mathrm{T}}$ channels and observed that the kinetic properties of these channels were similar in patches derived from the soma, stem, and higher order dendrites (Fig. 9A). The amplitude of ensemble currents, however, was found to be on average significantly larger (ANOVA, $p<0.05$ ) in recordings made from the stem dendrite compared with somatic and higher order dendritic locations (Fig. 9B). To our surprise we obtained
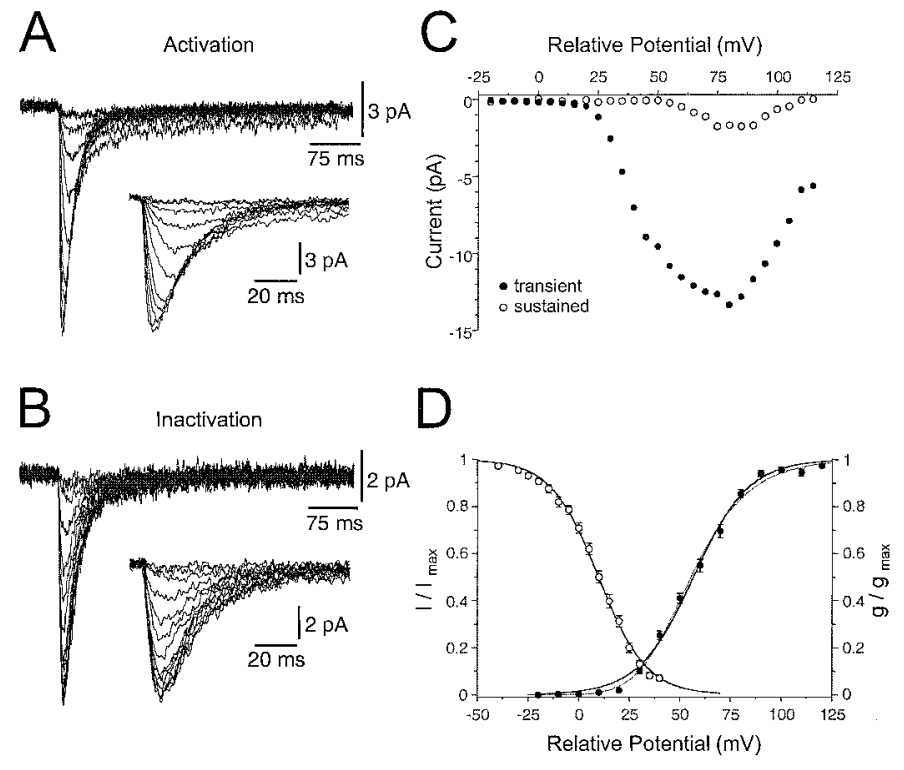

Figure 8. Steady-state properties of low-threshold calcium channels. $A$, Superposed cell-attached current traces used for the construction of steady-state activation curves during test pulses from +15 to $+65 \mathrm{mV}$ in $5 \mathrm{mV}$ steps. Each trace is an average of five trials. The inset shows the voltage-dependent activation kinetics of the current at a faster time base. $B$, A family of current traces used for the construction of steady-state inactivation curves during prepulses from -40 to $40 \mathrm{mV}$ in $10 \mathrm{mV}$ steps. The insets show the voltage-dependent kinetics of this current at a faster time base. $C$, Current-voltage relationship of the current shown in $A$ when measured at peak amplitude $(\bullet)$ or immediately before the termination of the test pulse $(\bigcirc) . D$, Pooled steady-state activation $(\bullet)$ and inactivation $(\bigcirc)$ curves; each point represents mean \pm SEM. The solid curves were fit with single Boltzmann functions (see Material and Methods). A better approximation of the activation curve was found by raising the Boltzmann function to the third power (dashed line). Note the voltage overlap between curves. Voltages are relative to resting membrane potential.

many somatic patches that did not show any, or demonstrated very little, calcium channel activity. Furthermore, little calcium channel activity was found in our most distal dendritic recordings (Fig. 9B).

When the voltage dependence of activation and steady-state inactivation were examined at different somato-dendritic locations, we observed a small parallel shift in the midpoint values of steady-state activation and inactivation curves (soma: $52.9 \mathrm{mV}$, activation, $4.5 \mathrm{mV}$, inactivation; primary dendrite branch: 59.6 $\mathrm{mV}$, activation, $11.92 \mathrm{mV}$, inactivation; all potentials are relative to RMP) in the depolarized direction for recordings made from the most distal sites (i.e., at dendritic branch points and from higher order dendrites) (Fig. 9C). These effects were not produced by differences in RMP between somatic and dendritic sites because we observed no noticeable differences in RMP across the somato-dendritic area examined. In summary, these data directly demonstrate that low-threshold calcium channels have a predominant dendritic distribution and that the profile of this distribution is nonuniform and highest in stem dendrites.

\section{Local dendritic regenerative activity}

We sought to explore whether a predominate dendritic location of $I_{\mathrm{T}}$ channels led to any unique effects when current was directly injected into the dendrites of TC neurons (Fig. 10). Simultaneous somatic and dendritic current-clamp recordings demonstrated that as the somatic membrane potential was changed by tonic 


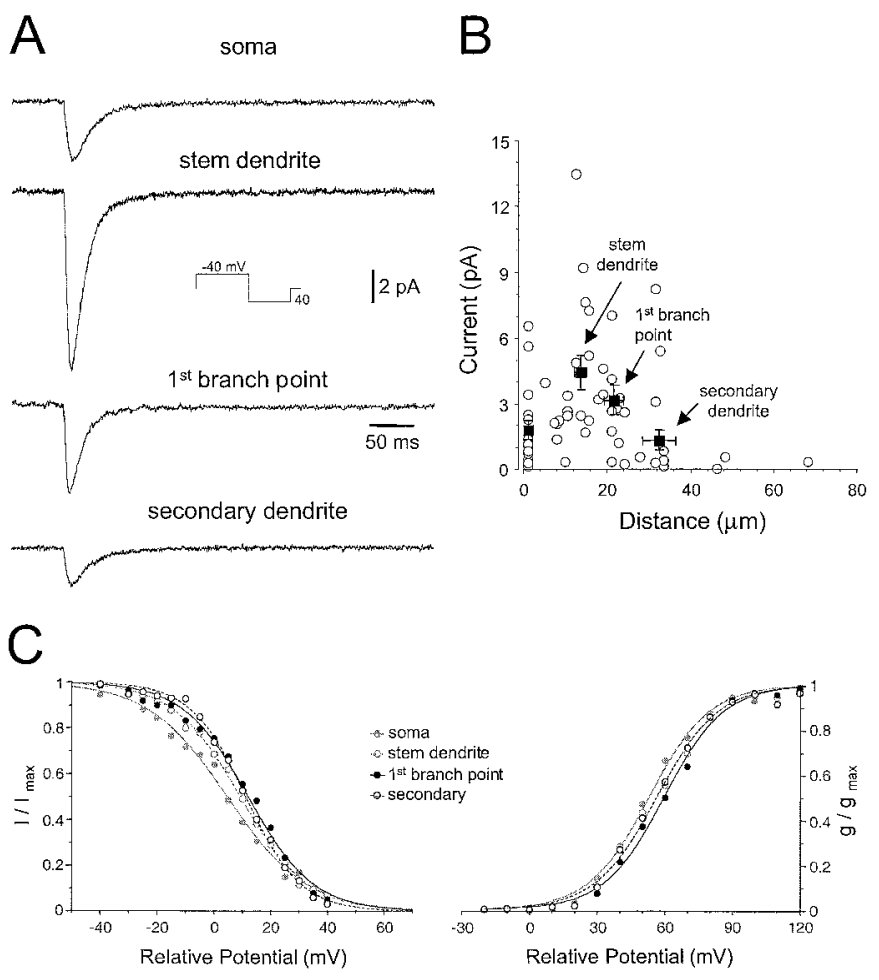

Figure 9. Somato-dendritic distribution and properties of low-threshold calcium channels. $A$, Selected averaged traces demonstrating the relationship between current amplitude and recording location. Note that the transient inward current is of the same kinetics at each recording location, but of relatively greater amplitude when recorded from stem dendrites. Somatic and stem dendritic patches were taken from the same neuron. $B$, Pooled data quantifying the relationship between current density and dendritic location. Each recording is shown as an open circle. Filled squares show mean $( \pm \mathrm{SD})$ current as a function of distance from the soma $( \pm \mathrm{SD})$ for recordings made from the soma, stem dendrites, primary branch points, and higher order dendrites (from left to right, respectively). $C$, Steady-state activation and inactivation curves constructed from data pooled by recording location, as shown in the inset. Note that more distal dendritic recordings yield activation and inactivation curves that are shifted to the right along the voltage axis. Voltages are relative to resting membrane potential.

somatic current injection, the firing response of TC neurons in response to small positive somatic current steps changed from single spike to the burst firing of action potentials in a voltagedependent manner, as has been described previously (Deschenes et al., 1982; Llinas and Jahnsen, 1982). This transformation was produced by the activation of an LTCP. When this experiment was repeated by controlling membrane potential with tonic current injection through the dendritic pipette and voltage responses were evoked by small positive dendritic current steps, a similar transformation of firing pattern was observed. The charging pattern of the membrane was altered (Fig. 10, right, arrows), however, in 5 of 30 recordings during dendritic current steps, as a consequence of the generation of smaller amplitude transient depolarizing potential that proceeded the full blown LTCP. This potential was of greatest amplitude when recorded locally in the dendrite and was significantly attenuated at the somatic recording site (Fig. 10). The voltage dependence of this local transient depolarizing potential was similar to that of the LTCP, suggesting that it is mediated by the activation of dendritic $I_{\mathrm{T}}$ channels. These data, therefore, suggest that local voltage-dependent pro-

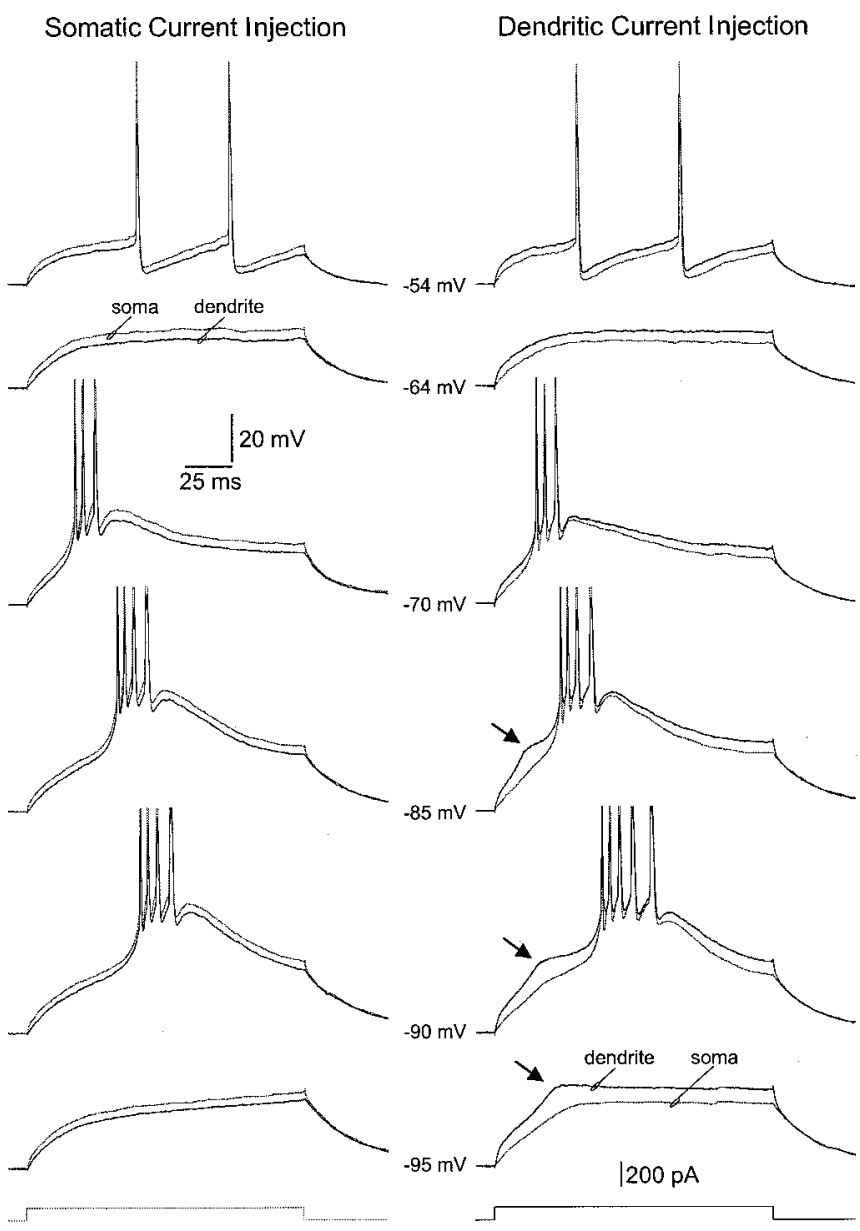

Figure 10. Local regenerative activity in the dendrites of TC neurons. All traces were recorded during simultaneous somatic (thin traces) and secondary dendritic recording. The membrane potential was controlled by tonic current injection through the somatic (left) or dendritic (right) electrode, and voltage responses were evoked by $100 \mathrm{pA}$ current steps (bottom traces) delivered to either the somatic (left) or dendritic (right) recording electrode. In response to somatic current injection the neuron showed a voltage-dependent firing pattern, characterized by the generation of a low-frequency train of action potentials at the most depolarized membrane potential and a burst of action potentials crowning a lowthreshold calcium potential at more hyperpolarized membrane potentials. In response to dendritic current injection, low-threshold calcium potentials are proceeded by a smaller transient depolarizing potential (arrows). This potential could be evoked in isolation at the most hyperpolarized test potential. Note the degree of attenuation of this transient depolarizing potential from dendrite to soma. The resting membrane potential of this neurons was $-70 \mathrm{mV}$.

cesses can occur in relative isolation in the dendrites of TC neurons.

\section{DISCUSSION}

We show that action potentials evoked by sensory or cortical EPSPs are initiated near the soma and actively backpropagate into the dendrites of TC neurons. Backpropagation is compromised, however, by the properties of dendritic branches coupled with a declining density of dendritic sodium channels, indicating that backpropagation may fail to effect synaptic integration in the distal dendrites of TC neurons. We further show that lowthreshold calcium channels are nonuniformly distributed in TC neuron dendrites. A high density of these channels at sites that are known to receive excitatory synaptic connections from pri- 
mary afferents suggests that $I_{\mathrm{T}}$ channels play a key role in the amplification of sensory input to TC neurons.

\section{Site of action potential initiation and active dendritic backpropagation}

Our simultaneous recordings demonstrated that action potentials were recorded first at the soma and subsequently in the dendrites of TC neurons. Because the axon of rat dLGN TC neurons arises from the soma (Grossman et al., 1973; Williams et al., 1996), these data indicate that action potentials are probably initiated at axonal sites, as shown in other central neurons (Stuart et al., 1997b). After axonal initiation, dendritic action potential backpropagation has been shown to be reliant on the activation of dendritic voltage-activated sodium channels in a number of central neurons (Johnston et al., 1996; Stuart et al., 1997b). The density of sodium channels in TC neurons was on average constant across recordings made from the soma to the first branch point of stem dendrites. In daughter dendrites, however, we observed a reduction in sodium channel density. The density of potassium channels underlying a fast transient $\left(I_{\mathrm{A}}\right.$-like $)$ current and more slowly inactivating delayed rectifier type current was found to be on average constant across the somatodendritic area examined, which corresponds to approximately one-half the path length of TC neuron dendrites. Such channel distributions appear to be unique, because in pyramidal neurons of the hippocampus and neocortex, potassium channels with different properties are differentially distributed between the soma and dendrites (Hoffman et al., 1997; Bekkers and Stuart, 1998). The measured channel densities should therefore be considered in future dendritic models of TC neurons (Lytton et al., 1996; Antal et al., 1997). The active nature of action potential backpropagation in TC neurons was confirmed by comparing dendritic voltage responses in the absence and presence of TTX. A decrease in sodium channel density in daughter dendrites may help to explain the observation that action potential backpropagation is compromised after the branching of stem dendrites. The control of action potential backpropagation, however, is influenced not only by channel densities but also by dendritic morphology.

\section{Influence of dendritic geometry}

Modeling studies have demonstrated that action potential propagation through branched cable structures is critically dependent on cable geometry (Goldstein and Rall, 1974; Luscher and Shiner, 1990; Manor et al., 1991; Hausser et al., 1998). Action potential propagation through a dichotomously branched uniformly excitable cable occurs without amplitude degradation if the input impedance of the parent cable matches that of the daughter cables (Goldstein and Rall, 1974). For a cable of infinite length, this relationship holds if the diameter of the cables after the branch raised to the power $3 / 2$ equals that of the parent cable raised to the power $3 / 2$, yielding a geometrical ratio (GR) that equals 1 (Goldstein and Rall, 1974). If GR is greater than 1, a time-delay and decrease in action potential amplitude at and after the branch point occurs (Goldstein and Rall, 1974; Luscher and Shiner, 1990; Manor et al., 1991). It should be noted that invasion of a particular branch of an axon or dendrite is influenced not only by the GR of the branch point that an action potential immediately encounters but by the GR of other more distal branch points, within certain electrotonic limits (Manor et al., 1991; Hausser et al., 1998), and that the summed influence of such mismatches is supralinear (Manor et al., 1991). Consistent with a deleterious effect of dendritic branching on action potential back- propagation, we find that a shallower relationship exists, on average, between backpropagating action potential amplitude and distance of dendritic recordings from soma along unbranched stem dendrites as compared with those made after branch points (Fig. 2). Furthermore, recordings made from the same dendrite before and after a branch point indicate that attenuation of action potentials over a finite distance is greater for a branching dendrite than for an unbranched dendrite.

Anatomical studies have demonstrated that the dichotomously branched dendrites of TC neurons do not obey Ralls power law (Kniffki et al., 1993; Ohara et al., 1995). The degree of variation from $\mathrm{GR}=1$ is dependent on the branch number; stem dendrites of TC neurons branch many times (average values between 7 and 25 , depending on species and nuclei) to form a large number (1 to $>40$ ) of terminal dendrites (Havton and Ohara, 1993; Kniffki et al., 1993; Ohara and Havton, 1994; Ohara et al., 1995). Average GR values of near 1 (but with scatter from 0.7-1.3) (Bloomfield et al., 1987), 1.4 (Ohara et al., 1995), and 1.72 (Kniffki et al., 1993) have been obtained at the first stem to nonterminal dendritic branch, whereas values $>4-5$ have been observed for more distal fifth to seventh order branches (Kniffki et al., 1993; Ohara et al., 1995). These data are therefore compatible with our electrophysiological findings and suggest that action potential backpropagation is controlled in TC neurons according to the following scheme: (1) impedance mismatch at dendritic branch points directly compromises backpropagation; (2) as a corollary more highly branched dendrites hamper backpropagation to a greater extent and (3) combined with the lower sodium channel density in daughter dendrites this forms a situation in which lower amplitude action potentials are less likely to activate a decreasing number of sodium channels. Backpropagating action potentials may therefore fail to invade the most distal dendrites of TC neurons. The filtering effects of dendritic branch points on action potentials of different rise and decay times generated during action potential burst firing are consistent with this scheme, because slower rising events will be expected to be filtered less by impedance mismatches at dendritic branch points.

One key function of backpropagating action potentials is thought to be the resetting of synaptic integration, produced as a consequence of the depolarization of dendrites decreasing the driving force for excitatory synaptic currents, and by shunting produced by the conductance changes associated with action potential generation (Stuart and Sakmann, 1994; Stuart et al., 1997b; Stuart and Hausser, 1998). Backpropagating action potentials in TC neurons may be capable of effecting the dendritic integration of the primary afferent and intrageniculate inhibitory inputs to these cells, which are made on stem dendrites or at sites close to the first dendritic branch points but may fail to effect inputs from cortical neurons made at distal dendritic sites (Sherman and Guillery, 1996). Backpropagation of action potentials in TC neurons might therefore lead to the resetting of dendritic integration of synaptic inputs that primarily determine the receptive field properties of TC neurons (Sherman and Guillery, 1998) while sparing inputs from the cortex that are thought to produce slower membrane potential changes that control response mode (i.e., single or burst firing of action potentials) (Sherman and Guillery, 1998).

\section{Distribution of calcium channels}

The low-threshold calcium current underlies many of the complex electrophysiological properties of TC neurons, including the generation of action potential burst firing, periodic oscillatory activ- 
ity, and membrane potential bistability (Llinas, 1988; Steriade et al., 1993; Williams et al., 1997). Furthermore, $I_{\mathrm{T}}$ has been shown to amplify subthreshold EPSPs and IPSPs (von Krosigk et al., 1993; Turner et al., 1994; Williams et al., 1997; Kim and McCormick, 1998). Our dendritic recordings indicate that $I_{\mathrm{T}}$ channels are at a high density in stem dendrites and stem dendritic branch points of TC neurons, with a lower and more patchy distribution at the soma. Furthermore, we failed to detect $I_{\mathrm{T}}$ channels in more distal secondary dendrites. Supportive of these findings, calcium imaging experiments have indicated the presence of low- and high-threshold calcium channel-mediated signals in the stem dendrites of TC neurons (Munsch et al., 1997; Zhou et al., 1997). The voltage dependence of steady-state activation and inactivation processes of dendritic $I_{\mathrm{T}}$ channels was found to be shifted in the depolarized direction at more distal recording locations. These properties would allow dendritic $I_{\mathrm{T}}$ channels to be activated at membrane potentials nearer firing threshold, and so extend the role of dendritic $I_{\mathrm{T}}$ channels in the amplification of synaptic inputs. Recent modeling studies have indicated that the electrophysiological properties of TC neurons may be reproduced if $I_{\mathrm{T}}$ channels are distributed dendritically with a uniform high density throughout their arbor (Destexhe et al., 1998). Our data, however, indicate that $I_{\mathrm{T}}$ channels are nonuniformly distributed. More extensive computer simulations are therefore required to ascertain the consequences of a nonuniform dendritic distribution of $I_{\mathrm{T}}$ channels.

In conclusion, we have directly demonstrated that the dendrites of TC neurons contain various voltage-activated ion channels and can support active backpropagation of action potentials and the generation of local dendritic regenerative activity. These channel distributions extend the functional repertoire of TC neurons and indicate that during wakefulness and sleep dendritic ion channels will influence synaptic integration and the generation of oscillatory activity in TC neurons.

\section{REFERENCES}

Antal K, Emri Z, Toth TI, Crunelli V (1997) Model of a thalamocortical neurone with dendritic voltage-gated ion channels. NeuroReport 8:1063-1066.

Bekkers JM, Stuart G (1998) Distribution and properties of potassium channels in the soma and apical dendrites of layer 5 cortical pyramidal neurons. Soc Neurosci Abstr 24:807.8.

Bloomfield SA, Hamos JE, Sherman SM (1987) Passive cable properties and morphological correlates of neurones in the lateral geniculate nucleus of the cat. J Physiol (Lond) 383:653-692.

Budde T, Munsch T, Pape HC (1998) Distribution of L-type calcium channels in rat thalamic neurones. Eur J Neurosci 10:586-597.

Coulter DA, Huguenard JR, Prince DA (1989) Calcium currents in rat thalamocortical relay neurones: kinetic properties of the transient, low-threshold current. J Physiol (Lond) 414:587-604.

Crunelli V, Kelly JS, Leresche N, Pirchio M (1987a) On the excitatory post-synaptic potential evoked by stimulation of the optic tract in the rat lateral geniculate nucleus. J Physiol (Lond) 384:603-618.

Crunelli V, Kelly JS, Leresche N, Pirchio M (1987b) The ventral and dorsal lateral geniculate nucleus of the rat: intracellular recordings in vitro. J Physiol (Lond) 384:587-601.

Crunelli V, Lightowler S, Pollard CE (1989) A T-type Ca2+ current underlies low-threshold $\mathrm{Ca} 2+$ potentials in cells of the cat and rat lateral geniculate nucleus. J Physiol (Lond) 413:543-561.

Deschenes M, Roy JP, Steriade M (1982) Thalamic bursting mechanism: an inward slow current revealed by membrane hyperpolarization. Brain Res 239:289-293.

Destexhe A, Neubig M, Ulrich D, Huguenard J (1998) Dendritic lowthreshold calcium currents in thalamic relay cells. J Neurosci 18:3574-3588.

Golding NL, Spruston N (1998) Dendritic sodium spikes are variable triggers of axonal action potentials in hippocampal CA1 pyramidal neurons. Neuron 21:1189-1200.
Goldstein SS, Rall W (1974) Changes of action potential shape and velocity for changing core conductor geometry. Biophys J 14:731-757.

Golshani P, Warren RA, Jones EG (1998) Progression of change in NMDA, non-NMDA, and metabotropic glutamate receptor function at the developing corticothalamic synapse. J Neurophysiol 80:143-154.

Grossman A, Lieberman AR, Webster KE (1973) A Golgi study of the rat dorsal lateral geniculate nucleus. J Comp Neurol 150:441-466.

Guido W, Weyand T (1995) Burst responses in thalamic relay cells of the awake behaving cat. J Neurophysiol 74:1782-1786.

Hausser M, Vetter P, Roth A (1998) Action potential backpropagation depends on dendritic geometry. Soc Neurosci Abstr 24:719.1.

Havton LA, Ohara PT (1993) Quantitative analyses of intracellularly characterized and labelled thalamocortical projection neurons in the ventrobasal complex of primates. J Comp Neurol 336:135-150.

Hernandez-Cruz A, Pape HC (1989) Identification of two calcium currents in acutely dissociated neurons from the rat lateral geniculate nucleus. J Neurophysiol 61:1270-1283.

Hoffman DA, Magee JC, Colbert CM, Johnston D (1997) $\mathrm{K}^{+}$channel regulation of signal propagation in dendrites of hippocampal pyramidal neurons. Nature 387:869-875.

Huguenard JR, Prince DA (1991) Slow inactivation of a TEA-sensitive $\mathrm{K}$ current in acutely isolated rat thalamic relay neurons. J Neurophysiol 66:1316-1328.

Huguenard JR, Coulter DA, Prince DA (1991) A fast transient potassium current in thalamic relay neurons: kinetics of activation and inactivation. J Neurophysiol 66:1304-1315.

Johnston D, Magee JC, Colbert CM, Cristie BR (1996) Active properties of neuronal dendrites. Annu Rev Neurosci 19:165-186.

Kim U, McCormick DA (1998) The functional influence of burst and tonic firing mode on synaptic interactions in the thalamus. J Neurosci 18:9500-9516.

Klee R, Ficker E, Heinemann U (1995) Comparison of voltagedependent potassium currents in rat pyramidal neurons acutely isolated from hippocampal regions CA1 and CA3. J Neurophysiol 74:1982-1995.

Kniffki K-D, Pawlak M, Vahle-Hinz C (1993) Scaling behavior of the dendritic branches of thalamic neurons. Fractals 1:171-178.

Llinas R (1988) The intrinsic electrophysiological properties of mammalian neurons: insights into central nervous system function. Science 242:1654-1664.

Llinas R, Jahnsen H (1982) Electrophysiology of mammalian thalamic neurones in vitro. Nature 297:406-408.

Luscher HR, Shiner JS (1990) Simulation of action potential propagation in complex terminal arborizations. Biophys J 58:1389-1399.

Lytton WW, Destexhe A, Sejnowski TJ (1996) Control of slow oscillations in the thalamocortical neuron: a computer model. Neuroscience 70:673-684.

Magee JC, Johnston D (1997) A synaptically controlled, associative signal for Hebbian plasticity in hippocampal neurons. Science 275:209-213.

Manor Y, Koch C, Segev I (1991) Effect of geometrical irregularities on propagation delay in axonal trees. Biophys J 60:1424-1437.

Mayer ML, Sugiyama K (1988) A modulatory action of divalent cations on transient outward current in cultured rat sensory neurones. J Physiol (Lond) 396:417-433.

McCormick DA (1992) Neurotransmitter actions in the thalamus and cerebral cortex and their role in neuromodulation of thalamocortical activity. Prog Neurobiol 39:337-388.

Mouginot D, Bossu JL, Gahwiler BH (1997) Low-threshold $\mathrm{Ca}^{2+}$ currents in dendritic recordings from Purkinje cells in rat cerebellar slice cultures. J Neurosci 17:160-170.

Munsch T, Budde T, Pape HC (1997) Voltage-activated intracellular calcium transients in thalamic relay cells and interneurons. NeuroReport 8:2411-2418.

Ohara PT, Havton LA (1994) Dendritic architecture of rat somatosensory thalamocortical projection neurons. J Comp Neurol 341:159-171.

Ohara PT, Ralston H, Havton LA (1995) Architecture of individual dendrites from intracellularly labelled thalamocortical projection neurons in the ventral posterolateral and ventral posteromedial nuclei of cat. J Comp Neurol 358:563-572.

Parri HR, Crunelli V (1998) Sodium current in rat and cat thalamocortical neurons: role of a non-inactivating component in tonic and burst firing. J Neurosci 18:854-867.

Perez Velazquez JL, Carlen PL (1996) Development of firing patterns and electrical properties in neurons of the rat ventrobasal thalamus. Brain Res Dev Brain Res 91:164-170. 
Ralston H, Herman MM (1969) The fine structure of neurons and synapses in ventrobasal thalamus of the cat. Brain Res 14:77-97.

Schiller J, Schiller Y, Stuart G, Sakmann B (1997) Calcium action potentials restricted to distal apical dendrites of rat neocortical pyramidal neurons. J Physiol (Lond) 505:605-616.

Sherman SM, Guillery RW (1996) Functional organization of thalamocortical relays. J Neurophysiol 76:1367-1395.

Sherman SM, Guillery RW (1998) On the actions that one nerve cell can have on another: distinguishing "drivers" from "modulators". Proc Natl Acad Sci USA 95:7121-7126.

Spruston N, Schiller Y, Stuart G, Sakmann B (1995) Activity-dependent action potential invasion and calcium influx into hippocampal CA1 dendrites. Science 268:297-300.

Steriade M, Deschenes M (1984) The thalamus as a neuronal oscillator. Brain Res 320:1-63.

Steriade M, McCormick DA, Sejnowski TJ (1993) Thalamocortical oscillations in the sleeping and aroused brain. Science 262:679-685.

Stuart G, Hausser M (1998) Shunting of EPSPs by action potentials. Soc Neurosci Abstr 24:718.3.

Stuart GJ, Sakmann B (1994) Active propagation of somatic action potentials into neocortical pyramidal cell dendrites. Nature 367:69-72.

Stuart G, Schiller J, Sakmann B (1997a) Action potential initiation and propagation in rat neocortical pyramidal neurons. J Physiol (Lond) 505:617-632.

Stuart G, Spruston N, Sakmann B, Hausser M (1997b) Action potential initiation and backpropagation in neurons of the mammalian CNS. Trends Neurosci 20:125-131.
Turner JP, Salt TE (1998) Characterization of sensory and corticothalamic excitatory inputs to rat thalamocortical neurones in vitro. J Physiol (Lond) 510:829-843.

Turner JP, Leresche N, Guyon A, Soltesz I, Crunelli V (1994) Sensory input and burst firing output of rat and cat thalamocortical cells: the role of NMDA and non-NMDA receptors. J Physiol (Lond) 480:281-295.

Verheugen JA, Fricker D, Miles R (1999) Noninvasive measurements of the membrane potential and GABAergic action in hippocampal interneurons. J Neurosci 19:2546-2555.

von Krosigk M, Bal T, McCormick DA (1993) Cellular mechanisms of a synchronized oscillation in the thalamus. Science 261:361-364.

Warren RA, Jones EG (1997) Maturation of neuronal form and function in a mouse thalamo-cortical circuit. J Neurosci 17:277-295.

Warren RA, Golshani P, Jones EG (1997) GABA(B)-receptormediated inhibition in developing mouse ventral posterior thalamic nucleus. J Neurophysiol 78:550-553.

Williams SR, Turner JP, Anderson CM, Crunelli V (1996) Electrophysiological and morphological properties of interneurones in the rat dorsal lateral geniculate nucleus in vitro. J Physiol (Lond) 490:129-147.

Williams SR, Toth TI, Turner JP, Hughes SW, Crunelli V (1997) The "window" component of the low threshold $\mathrm{Ca} 2+$ current produces input signal amplification and bistability in cat and rat thalamocortical neurones. J Physiol (Lond) 505:689-705.

Zhou Q, Godwin DW, O'Malley DM, Adams PR (1997) Visualization of calcium influx through channels that shape the burst and tonic firing modes of thalamic relay cells. J Neurophysiol 77:2816-2825. 